\title{
Air pollution inside public transport vehicles of Kathmandu Valley
}

\author{
NB Dhital ${ }^{1 *}$, WT Hung ${ }^{2}$, RM Byanju ${ }^{1}$ \\ ${ }^{1}$ Central Department of Environmental Science, Tribhuvan University, Kathmandu, Nepal \\ ${ }^{2}$ Department of Civil and Environmental Engineering \\ The Hong Kong Polytechnic University, Hong Kong SAR, China
}

\begin{abstract}
Owing to widespread road widening activities and the growing vehicular traffic, air quality of Kathmandu Valley has been a matter of grave concern. In this study, we monitored air quality inside public vehicles of Kathmandu Valley which would help assess the exposure of public transport users to air pollution. Problem of particulate pollution, especially $\mathrm{PM}_{10}$, was found severe inside the buses. Carbon monoxide and total volatile organic compounds were mostly within acceptable levels but benzene exceeded guidelines in few samples. Benzene, toluene, ethylbenzene and xylene (BTEX) were dominant among all detected volatile organic compounds. There was high degree of correlation among BTEX. Similarly, significant correlation was found between carbon monoxide and total volatile organic compounds. $\mathrm{PM}_{10}$ and $\mathrm{PM}_{2.5}$ were also significantly correlated suggesting common source of emission. Gaseous pollutants had significant negative correlation with traffic speed suggesting that traffic congestion (responsible for low traffic speed and high traffic density) is causing higher emission.
\end{abstract}

Key words: in-vehicle air quality; particulate matter; carbon monoxide, volatile organic compound

\section{Introduction}

Air pollution has been reported to pose a significant threat to human health worldwide (WHO, 2006). Most evidences have shown respiratory and cardiovascular effects of short and long term exposures to air pollutants (Pradhan et al., 2012; Shin et al., 2009; WHO, 2006; Wu et al., 2010). The effects may range from subtle biochemical and physiological changes to severe illnesses and death (WHO, 2006).

Vehicular emission is one of the major sources of air pollutants. Studies on traffic related pollution exposure have been increasing in number in recent years (Han \& Naeher, 2006). Some studies on exposure to in-vehicle air pollution have reported excess mortality and morbidity of vehicle drivers which are attributed to poor air quality inside vehicles (Hannerz \& Tüchsen, 2001; Zhang \& Batterman, 2013).

Commuters and vehicle drivers spend significant time inside vehicles and they are exposed to several types of air pollutants (Han et al., 2010; Hudda et al., 2012). So monitoring invehicle air quality is important for exposure assessment (Bigazzi \& Figliozzi, 2012). But most of the air pollution

*Corresponding author: email: nbdhital@cdes.edu.np studies have so far focused on outdoor air quality and there are limited studies on in-vehicle air quality. Thus research gap on air pollution inside vehicles has been specifically highlighted.

Particulate matter pollution has been found to be a major problem in Kathmandu Valley (Aryal et al., 2008). But the problem has been further exacerbated by the road widening projects which are currently undergoing in the Valley. There are no effective actions to suppress dusts and other emissions during the road constr uction period and problem of particulate pollution has risen substantially throughout the Valley. Since several air quality monitoring stations of Valley are cur rently out of function, scientific data on V alley's air quality is inadequate to understand the problem.

In this study, particulate matter $\left(\mathrm{PM}_{10}\right.$ and $\left.\mathrm{PM}_{2.5}\right)$, carbon monoxide (CO) and volatile or ganic compounds (VOC) were monitored inside public buses. The study provides scenario of in-vehicle air quality in public vehicles of Kathmandu Valley. The outcomes may help for mulate improvement plans. 


\section{Materials and Methods}

Study area

In order to have a meaningful comparison, public vehicles on three routes with various traffic intensity were sampled (Fig.1).

\section{Sajha Yatayat route}

This route is $13.8 \mathrm{~km}$ long (New Bus Park to Lagankhel Bus Park) and characterized by high traffic density , traffic congestion and low traffic speed. It passes through the core area of Kathmandu City. Traffic composition is dominated by motorbikes, microbuses, buses and private vehicles. Some sections of this route were being widened during field sampling. The road widening activities included demolition of buildings, infrastructures and reconstruction and repaving of road. These activities had resulted in dusty atmosphere in the surrounding area. Intensive construction activities were undergoing in the section between New Bus Park and Lainchaur.

\section{Ring Road section}

This route is $14 \mathrm{~km}$ long (New Bus Park to Satdobato) and characterized by medium traffic density. Traffic congestions are observed during peak traffic hours in major intersections. Traffic speed is relatively higher. Roads are relatively wider but the major sections of road are being expanded and dust in air is common.

\section{Godawari route}

This $10.3 \mathrm{~km}$ route (L agankhel Bus Park to Godawari) connects central part of city i.e. L agankhel Bus Park with the suburban area of Godawari. V ehicles are mainly microbuses, motorbikes and few trucks. Though the road is narrow, road condition is relatively better than in Sajha Yatayat route and Ring Road section. Traffic congestion is less common except in L agankhel-Satdobato section.

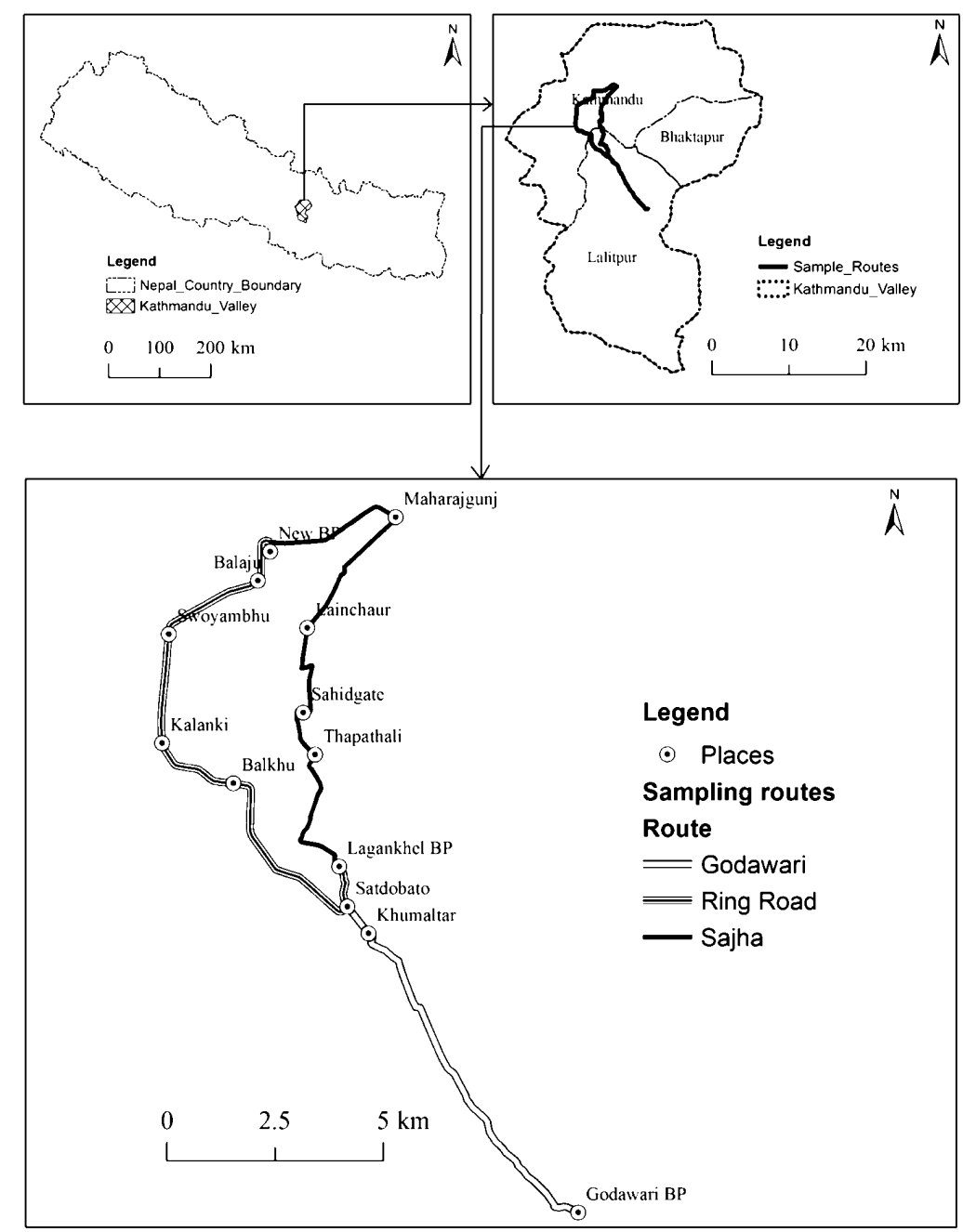

Fig. 1 Study area showing the sampling routes 


\section{Sample vehicles}

Eleven buses were sampled from each of Sajha Yatayat and Ring Road routes while 12 microbuses were sampled from Godawari route. But some of the parameters couldn't be measured in few samples due to technical problem and data for at least 9 samples for each parameter were available for analysis. All sample vehicles of Sajha route were Euro III buses and all of these buses were about 1 year old. Average age of vehicles sampled in Ring Road was 8 years (ranging from 5 to 14 years) while it was 13 years (ranging from 5 to 26 years) in Godawari route. Ring Road samples were minibuses and Godawari samples were microbuses.

\section{On-site air quality monitoring}

Air quality sampling was done between 07:00 and 18:00 in March 2014. Sampling duration ranged from about 25 to 80 minutes depending on the route length and traffic speed. $\mathrm{PM}_{10}$ and $\mathrm{PM}_{2.5}$ were measured by using portable TSI Dust Trak Aerosol Monitors (Model 8520). These aerosol monitors use light scattering technology to measure real-time mass concentration and have detection limit of $1 \mu \mathrm{g} / \mathrm{m}^{3}$. PM concentrations were averaged and recorded at an inter val of 1 minute. CO was measured by using Interscan CO Monitor (Model 4143) which mak es use of electrochemical voltammetric sensing technology and has a detection limit of 0.1 ppm (Man, 2001). Data logger was used to record 1 minute average concentration of CO. Real time monitoring of total volatile organic compounds (TVOC) was done by using ppbRAE Volatile Organic Compound Monitor (Model PGM-7240) which works by using Photo Ionization Detection (PID) technology. These equipments were calibrated in the laboratory of The Hong Kong Polytechnic University before taking them to Nepal for measurements. Regular zeroing was done for DustTrack and CO monitors.

\section{Air sampling for VOCs}

Air samples were collected in SUMMA stainless steel canisters for laboratory analysis of VOC species (six samples from each of Sajha and Ring Road and five samples from Godawari). The canisters were cleaned and evacuated before sampling by using Canister Cleaning System in the laboratory of The Hong Kong Polytechnic University and these were shipped to Nepal for sampling. The flow rate was adjusted to fill the canisters up to atmospheric pressure in 30 minutes. Canister samples were shipped back to Hong Kong for analysis. The air samples were analyzed in the laborator y for different VOCs by using a system of a cryogenic concentrator (Nutech, Model 3550A), a gas chromatography (GS) (Hewlett Packard, 6890) and a mass selective detector (MSD) (Hewlett Packard, 5973). Retention time and mass spectra were used for identification of compounds. Analysis of VOCs was done in accordance with the USEPA Method TO-14.

\section{Temperature}

Temperature inside vehicle during sampling was measured by using mercury thermometer.

\section{Traffic speed}

Time taken by each sample vehicle to travel along sample route was recorded. Length of sample route was obtained from Google Earth. Average traffic speed was then calculated by dividing route length by time.

\section{Statistical analysis}

Descriptive statistics were calculated and analyzed for pollutant concentration. One-way ANOVA was used to test the difference in mean in-vehicle pollutant concentrations among three sampling routes and Tukey HSD test was used for pair-wise comparison. Correlation analysis was done for identifying the relationships between pollutants, if any.

\section{Results and Discussion}

Table 1 summarizes the mean concentration of in-vehicle $\mathrm{PM}_{10}, \mathrm{PM}_{2.5}$, CO and TVOC in public transport vehicles of Sajha Yatayat, Ring Road and Godawari routes.

\section{Particulate matter (PM)}

In-vehicle $\mathrm{PM}_{10}$ concentration ranged from $164 \mu \mathrm{g} / \mathrm{m}^{3}$ to 612 $\mu \mathrm{g} / \mathrm{m}^{3}$ while $\mathrm{PM}_{2.5}$ concentration ranged from $48 \mu \mathrm{g} / \mathrm{m}^{3}$ to $202 \mu \mathrm{g} / \mathrm{m}^{3}$ among all samples. Mean concentrations of both $\mathrm{PM}_{10}$ and $\mathrm{PM}_{2.5}$ were found highest in Ring Road buses and least in Godawari buses (Fig.2, Fig.3).

Table 1. Concentration of air pollutants inside public buses of three routes (Mean \pm S.D.)

\begin{tabular}{llll}
\hline Parameters & \multicolumn{1}{c}{ Sajha } & \multicolumn{1}{c}{ Ring Road } & \multicolumn{1}{c}{ Godawari } \\
\hline $\mathrm{PM}_{10}\left(\mu \mathrm{g} / \mathrm{m}^{3}\right)$ & $275 \pm 89(\mathrm{n}=11)$ & $363 \pm 109(\mathrm{n}=10)$ & $213 \pm 44(\mathrm{n}=11)$ \\
$\mathrm{PM}_{2.5}\left(\mu \mathrm{g} / \mathrm{m}^{3}\right)$ & $92 \pm 48(\mathrm{n}=9)$ & $112 \pm 28(\mathrm{n}=9)$ & $68 \pm 15(\mathrm{n}=9)$ \\
$\mathrm{CO}(\mathrm{ppm})$ & $4.0 \pm 0.8(\mathrm{n}=11)$ & $2.8 \pm 0.9(\mathrm{n}=11)$ & $1.9 \pm 1.0(\mathrm{n}=11)$ \\
TVOC $(\mathrm{ppb})$ & $222 \pm 35(\mathrm{n}=11)$ & $185 \pm 28(\mathrm{n}=10)$ & $169 \pm 39(\mathrm{n}=12)$ \\
\hline
\end{tabular}

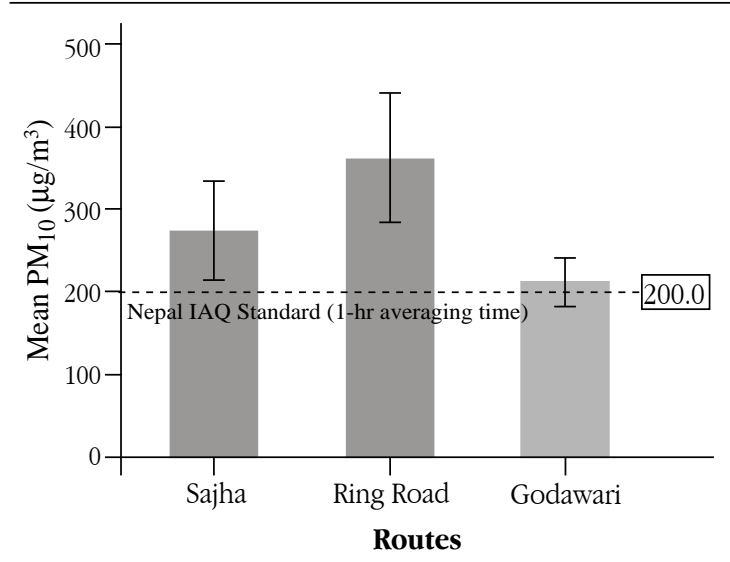

Fig. 2 Mean in-vehicle $\mathrm{PM}_{10}$ concentration in buses of three routes (error bars represent 95\% confidence intervals of means) 


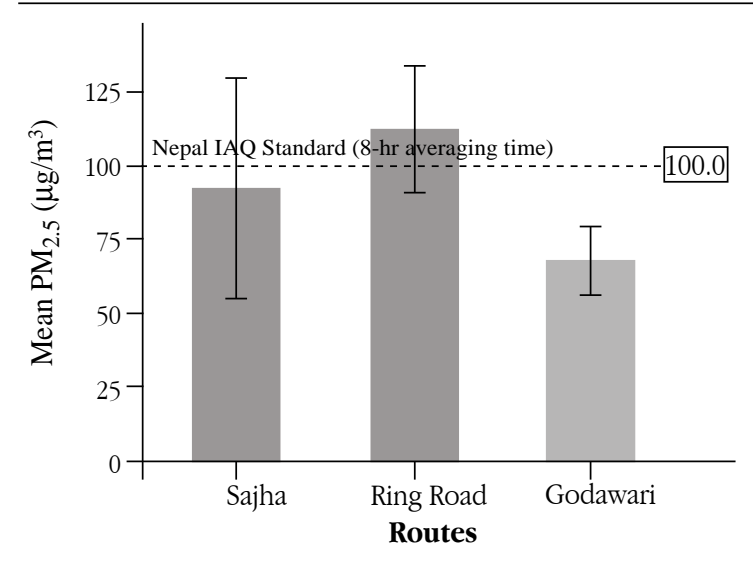

Fig. 3 Mean in-vehicle $\mathrm{PM}_{2.5}$ concentration in buses of three routes (error bars represent 95\% confidence intervals of means)

A significant difference in mean in-vehicle $\mathrm{PM}_{10}$ concentration was found between Ring Road and Godawari (Tukey HSD, $P=0.001)$. There might be numerous factors causing difference in PM pollution in buses of three routes but the number one factor might be road construction work. Road condition in a section of Ring Road (Balkhu-Satdobato) was poor with damaged pavement and demolition waste piles on the sides of road at several places during sampling. Road widening work was in progress in Sajha route too but the road condition was better as most of the expanded road sections had been already paved. The road of Godawari route was mostly paved. Second factor could be the traffic composition. Ring Road traffic composition is dominated by Heavy trucks and buses while Sajha route has mostly lighter vehicles and buses. Godawari route has mixed type of vehicles but the traffic flow is quite less as it mostly occurs in suburban area. Heavy tr ucks and buses of Ring Road might have caused higher re-suspension dust in the air Thus road condition in combination with traffic composition and flow could be the reason behind highest particulate pollution in Ring Road buses and least in Godawari.

Nepal's National Indoor Air Quality (IAQ) Standards and Implementation Guideline (MoEST, 2009) suggests the acceptable concentration of $\mathrm{PM}_{10}$ as $200 \mu \mathrm{g} / \mathrm{m}^{3}$ for 1 hour averaging time. All samples of Ring Road exceeded this guideline while $27.3 \%$ and $54.6 \%$ samples of Sajha Yatayat and Godawari respectively complied with this guideline. Based on the Hong Kong IAQ Objectives for $\mathrm{PM}_{10}, 9.1 \%$ and 27.3\% samples of Sajha and Godawari respectively were in good class $\left(<180 \mu \mathrm{g} / \mathrm{m}^{3}\right)$ while none of the samples of Ring Road were in good class. In case of $\mathrm{PM}_{2.5}, 77.8 \%, 33.3 \%$ and $100 \%$ of the samples of Sajha, Ring Road and Godawari respectively complied with Nepal's IAQ standards of $\mathrm{PM}_{2.5}$ (100 $\mu \mathrm{g} / \mathrm{m}^{3}$ for 1 hour averaging time). Based on WHO air quality guidelines, all samples were beyond the limits for $\mathrm{PM}_{10}$ and $\mathrm{PM}_{2.5}$.
Comparison of compliance status of $\mathrm{PM}_{10}$ and $\mathrm{PM}_{2.5}$ shows that the coarser particulate pollution is more severe. Previous study on ambient air pollution has also reported that monthly average $\mathrm{PM}_{10}$ in urban areas of $\mathrm{K}$ athmandu Valley even exceeded the daily standard level (Ar yal et al., 2008). In current scenario, an immediate action is needed to mitigate particulate pollution in air resulting from road widening works. High PM pollution found in present study might be the effect of season too as this monitoring was done in late winter (March) which is generally characterized by high level of pollution over Valley (Aryal et al., 2008).

\section{Carbon monoxide (CO)}

Average CO concentration ranged from $0.9 \mathrm{ppm}$ to $5.4 \mathrm{ppm}$ among all samples. Buses of Sajha route showed highest and buses of Godawari showed lowest mean in-vehicle CO concentration (Fig. 4).

One way ANOVA revealed significant difference in mean CO between at least a pair of routes $(P=0.000)$ and Tukey HSD post hoc test showed significant difference between Sajha and Godawari $(P=0.000)$ and Sajha and Ring Road $(P=0.010)$. There was no significant difference between Godawari and $\operatorname{Ring} \operatorname{Road}(P=0.082)$ at 0.05 level. Vehicle exhaust is a major source of CO in urban areas. Sajha route is characterized by frequent traffic congestions at most of the intersections leading to high traffic density and slow traffic speed and thus it had highest average in-vehicle CO concentration. But these factors have moderate action in Ring Road and least in Godawari leading to moderate CO pollution in for mer and least in later.

In-vehicle CO pollution was not found severe as all samples complied with CO guideline suggested by National IAQ Standards 2009 of Nepal (35 ppm for 1 hour and 9 ppm for 8 hours averaging time) and WHO guidelines (WHO, 2010). All samples were in Good Class (<8.7 ppm) based on IAQ Objectives of Hong Kong (IAQ Management Group, 2003); while $9.09 \%$ samples of Ring Road and 36.36\% samples of Godawari route were even in excellent class $(<1.7 \mathrm{ppm})$.

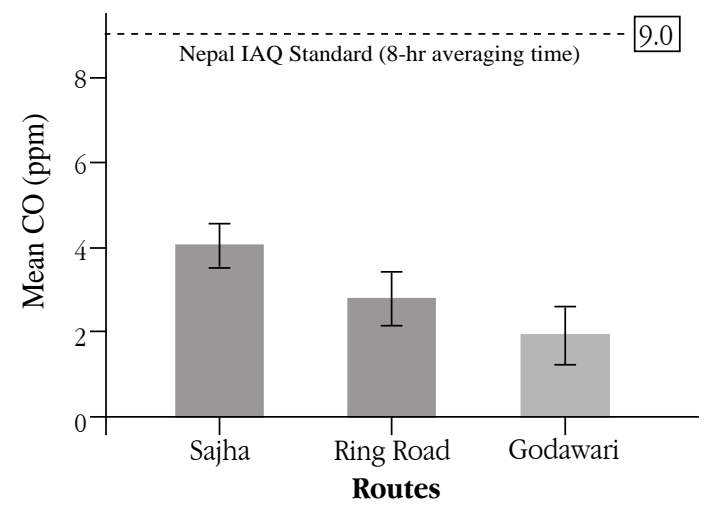

Fig. 4 Mean in-vehicle CO concentration in buses of three routes (error bars represent 95\% confidence intervals of means) 


\section{Total volatile organic compounds (TVOC)}

Average in-vehicle TVOC ranged from $116 \mathrm{ppm}$ to $279 \mathrm{ppm}$. ANOVA followed by post-hoc test showed significant difference between Sajha and Godawari ( $\mathrm{T}$ ukey HSD, $P=0.003)$. There was no significant difference between Godawari and Ring Road (Tukey HSD, $P=0.082$ ) and Ring Road and Sajha (Tukey HSD, $P=0.056$ ). Comparison of mean TVOC concentrations in three routes showed a patter $n$ similar to that of mean CO concentration. Highest mean TVOC was found in Sajha and least mean TVOC was found in Godawari route (Fig. 5). This difference can be explained by the severity of traffic congestions and traffic densities in three routes. As discussed earlier traffic density is quite high in Sajha route compared to that of Godawari route which might have caused highest in-vehicle TVOC in Sajha route.

\section{Volatile organic compounds (VOCs)}

Canister samples were analyzed in laboratory for 41 VOCs. Among these 41 compounds, a total of 39 compounds were detected in samples. These 39 VOCs were further analyzed for their relative proportions and it was found that BTEX (benzene, toluene, ethylbenzene and xylene) were dominant compounds. Among BTEX, toluene had highest concentration. A similar result has been found in roadside air of Hong Kong (Chan et al., 2002; Ho et al., 2002). Mean BTEX concentrations in present study were slightly higher than those reported in roadside air of Hong Kong (Ho et al., 2002) while it was lower than those reported in Guangzhou and Macau (W ang et al., 2002). Mean concentrations of BTEX in present study were quite lower than driver's exposure levels to BTEX in Korean public buses (Jo \& Yu, 2001). Combined BTEX proportions were 63.5\%, 62.8\% and 48.0\% in Sajha, Ring Road and Godawari samples respectively. Lee et al. (2002) reported the proportion of BTEX in ambient air of Hong Kong to be more than 60\%. In present study Sajha and Ring Road had BTEX proportion quite similar to that of Hong Kong but Godawari was different in ter ms of BTEX proportion. BTEX ratios of mass concentrations were calculated relative to ethylbenzene (Table 2). X:E ratios were same for all routes (i.e. 2.7). Close $\mathrm{X}$ :E ratios over study sites have been reported by Wang et al. (2002) too. B:E and T:E ratios were also similar in three routes suggesting the similarity in emission sources that could be primarily vehicular emissions and gasoline vapour.

Table 2. Average BTEX ratios relative to ethylbenzene

\begin{tabular}{lcccc}
\hline Sites & B & T & E & X \\
\hline Sajha & 1.6 & 6.1 & 1.0 & 2.7 \\
Ring Road & 2.2 & 6.8 & 1.0 & 2.7 \\
Godawari & 1.9 & 6.0 & 1.0 & 2.7 \\
All samples & 1.8 & 6.2 & 1.0 & 2.7 \\
\hline
\end{tabular}

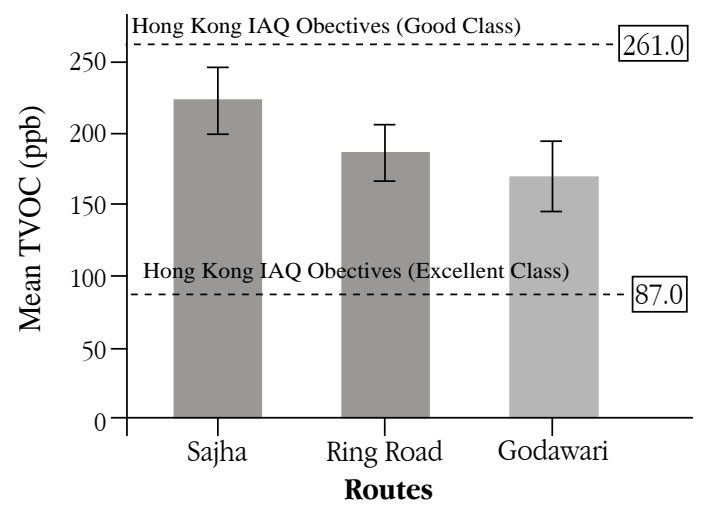

Fig. 5 Mean in-vehicle TVOC concentration in buses of three routes (error bars represent 95\% confidence intervals of means)

Average toluene to benzene ratio (T:B) was found 3.1 for whole samples and it was 3.2, 3.0 and 3.2 for Sajha, Ring Road and Godawari samples respectively. These ratios are slightly higher than those reported in roadside microenvironments of Hong Kong (Chan et al., 2002).

Ten VOCs are regulated by Hong Kong's IAQ Objectives (IAQ Management Group, 2003) and the mean concentrations of these compounds are compared with guidelines (Table 3). Two out of six samples of Sajha exceeded the guideline for Benzene $\left(16.1 \mu \mathrm{g} / \mathrm{m}^{3}\right.$ for good class) while all samples of Ring Road and Godawari were below this guideline. But IAQ guideline of WHO (WHO, 2010) does not recommend any safe level of exposure for benzene. Benzene pollution may pose threat to health of commuters and drivers of Sajha bus as it is a genotoxic carcinogen in humans (WHO, 2010). Invehicle benzene might be contributed by vehicle emissions, gasoline vapour and paintings inside vehicle. Mean as well as all individual sample concentrations of carbon tetrachloride, chloroform, 1,2-dichlorobenzene, 1,4-dichlorobenzene, ethylbenzene, tetrachloroethylene, toluene, trichloroethylene and xylene were well below the guideline values.

\section{Correlations among pollutants}

Pearson correlations among $\mathrm{PM}_{10}, \mathrm{PM}_{2.5}, \mathrm{CO}$ and TVOC are presented in Table 4. While in-vehicle CO is mostly contributed by vehicular emission, in-vehicle TVOC could have multiple sources in addition to vehicular emissions. But, a good correlation found between TVOC and CO suggests that the major source of emission of both pollutants is common which might be vehicular emission. High degree of correlation was found between $\mathrm{PM}_{10}$ and $\mathrm{PM}_{2.5}$. It suggests that the major sources of $\mathrm{PM}_{10}$ and $\mathrm{PM}_{2.5}$ are common which could be re-suspension dust from road. Such cor relations have been reported by previous studies on traffic air pollution (Bathmanabhan \& Madanayak, 2010). But PM 10 was not 
Table 3. Mean concentration of VOCs $\left(\mu \mathrm{g} / \mathrm{m}^{3}\right)$ regulated by Hong Kong (HK) IAQ Objectives inside the buses of three routes

\begin{tabular}{|c|c|c|c|c|}
\hline "g & $\begin{array}{l}\text { HK-IAQ } \\
\text { Objective for } \\
\text { "good class" } \\
\left(\mu \mathrm{g} / \mathrm{m}^{3}\right)\end{array}$ & $\begin{array}{l}\text { Sajha } \\
(n=6)\end{array}$ & $\begin{array}{l}\text { Ring Road } \\
(n=6)\end{array}$ & $\begin{array}{l}\text { Godawa } \\
(n=5)\end{array}$ \\
\hline Benzene & 16.1 & 14.70 & 8.28 & 6.13 \\
\hline Toluene & 1,092 & 54.20 & 25.14 & 18.91 \\
\hline Ethylbenzene & 1,447 & 8.96 & 3.71 & 3.16 \\
\hline Xylene & 1,447 & 23.96 & 9.87 & 8.45 \\
\hline Trichloroethylene & 770 & 0.04 & 0.02 & 0.02 \\
\hline Tetrachloroethylene & 250 & 0.02 & Not detected & 0.03 \\
\hline Carbon tetrachloride & le 103 & 0.16 & 0.25 & 0.28 \\
\hline Chloroform & 163 & 1.06 & 0.04 & 0.17 \\
\hline 1,2-Dichlorobenzene & he 500 & 0.36 & 0.16 & 0.23 \\
\hline 1,4-Dichlorobenzene & he 200 & 0.02 & Not detected & 0.02 \\
\hline
\end{tabular}

significantly correlated with gaseous pollutants while $\mathrm{PM}_{2.5}$ showed small but significant cor relations with TVOC and CO. These results are quite reasonable because road dust contributes to coarse particles lik e $\mathrm{PM}_{10}$ as well as fine particles like $\mathrm{PM}_{2.5}$ while vehicular emission contributes to gaseous pollutants like TVOC and CO and a fraction of finer particles like $\mathrm{PM}_{2.5}$ too.

Pearson correlations among BTEX showed all correlations were statistically significant which ranged from 0.574 to 0.991 (Table 5). BTEX correlation range has been found 0.71 to 0.98 in roadside air of Hong Kong (Ho et al., 2002). Similar results have been reported by Lau and Chan (2003) in their study on in-vehicle air quality in Hong Kong. High degree of correlation suggests the common sources of emission (Ho et al., 2002; Wang et al., 2002) which could be vehicular emission and gasoline vapours in present study.

Table 4. Pearson correlations among $\mathrm{PM}_{10}, \mathrm{PM}_{2.5}, \mathrm{CO}$ and TVOC

\begin{tabular}{lllll}
\hline Parameters & \multicolumn{1}{c}{$\mathbf{P M}_{\mathbf{1 0}}$} & $\mathbf{P M}_{\mathbf{2 . 5}}$ & $\mathbf{C O}$ & TVOC \\
\hline $\mathrm{PM}_{10}$ & 1 & & & \\
& $\mathrm{~N}=32$ & & & \\
PM2.5 & $0.806^{* *}$ & 1 & & \\
& $P=0.000$ & & & \\
& $\mathrm{~N}=27$ & $\mathrm{~N}=27$ & & \\
$\mathrm{CO}$ & 0.297 & $0.429^{*}$ & 1 & \\
& $P=0.105$ & $P=0.029$ & & \\
& $\mathrm{~N}=31$ & $\mathrm{~N}=26$ & $\mathrm{~N}=33$ & \\
TVOC & 0.241 & $0.532^{* *}$ & $0.743^{* *}$ & 1 \\
& $P=0.192$ & $P=0.005$ & $P=0.000$ & \\
& $\mathrm{~N}=31$ & $\mathrm{~N}=26$ & $\mathrm{~N}=32$ & $\mathrm{~N}=33$ \\
\hline
\end{tabular}

*Significant at $\alpha=0.05 ; * *$ Significant at $\alpha=0.01$
Table 5. Pearson correlations among Benzene, Toluene, Ethylbenzene and Xylene

\begin{tabular}{lllll}
\hline Parameters & Benzene & Toluene & Ethylbenzene & Xylene \\
\hline Benzene & 1 & & & \\
Toluene & $\mathrm{N}=17$ & & & \\
& $0.648^{* *}$ & 1 & & \\
& $P=0.005$ & & & \\
\multirow{4}{*}{ Ethylbenzene } & $\mathrm{N}=17$ & $\mathrm{~N}=17$ & & \\
& $0.611^{* *}$ & $0.980^{* *}$ & 1 & \\
& $P=0.009$ & $P=0.000$ & & \\
Xylene & $\mathrm{N}=17$ & $\mathrm{~N}=17$ & $\mathrm{~N}=17$ & \\
& $0.574^{*}$ & $0.991^{* *}$ & $0.989^{* *}$ & 1 \\
& $P=0.016$ & $P=0.000$ & $P=0.000$ & \\
& $\mathrm{~N}=17$ & $\mathrm{~N}=17$ & $\mathrm{~N}=17$ & $\mathrm{~N}=17$ \\
\hline *Significant at $\alpha=0.05$;* *Significant at $\alpha=0.01$ & &
\end{tabular}

\section{Vehicle age and in-vehicle air pollution}

Correlation of in-vehicle pollution level with vehicle age was explored but no sensible cor relations were found. In fact, all samples of Sajha were about 1 year old while most of the samples of Godawari were more than 10 years old. But both of mean CO and mean TVOC were found highest in Sajha and least in Godawari. In present study, the effect of vehicle age on in-vehicle air quality might have been mask ed by high ambient pollution levels.

\section{Vehicle speed and in-vehicle air pollution}

A negative correlation was found between average speed of vehicle during sampling and average in-vehicle CO level (Pearson correlation $=-0.630, P=0.000$ ). Similarly, a negative correlation was found between average speed and average in-vehicle TVOC level too (P earson correlation $=-0.448$, $P=0.009)$. Lower speed usually represents higher traffic density (Bigazzi \& Figliozzi, 2012) and more traffic congestions which might have caused high CO and TVOC pollution inside the buses.

\section{Conclusion}

Mean in-vehicle $\mathrm{PM}_{10}$ and $\mathrm{PM}_{2.5}$ concentrations were found highest in Ring Road and lowest in Godawari route. Particulate matter, especially $\mathrm{PM}_{10}$ inside buses frequently exceeded the guidelines. This could be the effect of re-suspension of dust from demolition waste resulting from road widening works. It can be concluded that paving all demolished roads could significantly reduce the particulate pollution. A total of 39 VOCs were detected in the air samples with BTEX forming a major component. Benzene concentration exceeded guidelines in few buses while remaining VOCs detected in sample were well below guideline values. TVOC and $\mathrm{CO}$ were also mostly within guidelines. TVOC and CO were negatively correlated with average traffic speed (affected mostly by traffic congestions). So these pollutants could be expected to lower with the completion of road widening projects and proper traffic management in Kathmandu Valley. 


\section{Acknowledgements}

The authors would like to thank Fredskorpset Norway for providing fund, under FK exchange program 2014, for this study, The Hong Kong Polytechnic University, Hong Kong for providing equipment and technical support and Clean Energy Nepal for coordinating the fieldwork and helping in shipment of samples. We acknowledge Mr. Sumann Udas, Mr. Prashanta Khanal, Ms. Rassu Manandhar and Mr. Damadar Dhital for coordinating the fieldwork. Authors are equally thankful to Mr. Sudeep Bhandari, Ms. Khusbu Poudel, Ms. Nicky Shrestha, Mr. Jadishwor Shrestha, Mr. Ronish Shakya, Ms. Rashmi Maharjan, Ms. Suchana Timalsina, Ms. Neha Shrestha, Ms. Srijana K atuwal, Ms. Suman Shrestha and Mr. Prakash Maharjan who provided help during sampling.

\section{References}

Aryal, R.K., Lee, B.K., Karki, R., Gurung, A., Kandasamy, J., Pathak, B.K., Sharma, S. \& Giri, N. (2008). Seasonal PM $_{10}$ dynamics in Kathmandu Valley. Atmospheric Environment, 42, 8623-8633.

Bathmanabhan, S. \& Madanayak, S.N.S. (2010). Analysis and interpretation of particulate matter- $\mathrm{PM}_{10}, \mathrm{PM}_{2.5}$ and $\mathrm{PM}_{1}$ emissions from the heterogeneous traffic near an urban roadway. Atmospheric Pollution Research, 1, 184-194.

Bigazzi, A.Y. \& Figliozzi, M.A. (2012). Impacts of freeway traffic conditions on in-vehicle exposure to ultrafine particulate matter. Atmospheric Environment, 60, 495-503.

Chan, C.Y., Chan, L.Y., Wang, X.M., Liu, Y.M., Lee, S.C., Zou, S.C., Sheng, G.Y. \& Fu, J.M. (2002). Volatile organic compounds in roadside microenvironments of metropolitan Hong Kong. Atmospheric Environment, 36, 2039-2047.

Han, X. \& Naeher, L.P. (2006). A review of traffic-related air pollution exposure assessment studies in the developing world. Environment International, 32, 106-120.

Han, Y.Y., Donovan, M. \& Sung, F.C. (2010). Increased urinary 8hydroxy-2'-deoxyguanosine excretion in long-distance drivers in Taiwan. Chemosphere, 79, 942-948.

Hannerz, H. \& Tüchsen, F. (2001). Hospital admissions among male drivers in Denmark. Occup Environ Med, 58, 253-260.

Ho, K.F., Lee, S.C. \& Chiu, G.M.Y. (2002). Characterization of selected volatile organic compounds, polycyclic aromatic hydrocarbons and carbonyl compounds at a roadside monitoring station. Atmospheric Environment, 36, 57-65.

Hudda, N., Eckel, S.P., Knibbs, L.D., Sioutas, C., Delfino, R.J. \& Fruin, S.A. (2012). Linking in-vehicle ultrafine particle exposures to on-road concentrations. Atmospheric Environment, 59, 578586.
IAQ Management Group (2003). A Guide on Indoor Air Quality Certification Scheme for Offices and Public Places. IAQ Management Group, The Government of the Hong Kong Special Administrative Region.

Jo, W.K. \& Yu, C.H. (2001). Public bus and taxicab drivers' exposure to aromatic work-time volatile organic compounds. Environmental Research Section, A 86, 66-72.

Lau, W.L. \& Chan, L.Y. (2003). Commuter exposure to aromatic VOCs in public transportation modes in Hong Kong. The Science of the Total Environment, 308, 143-155.

Lee, S.C., Chiu, M.Y., Ho, K.F., Zou, S.C. \& Wang, X. (2002). Volatile organic compounds (VOCs) in urban atmosphere of Hong Kong. Chemosphere, 48, 375-382.

Man, L.Y. (2001). A study on the buman exposure in various transportation modes in Hong Kong (Unpublished M. Phil Thesis), The Hong Kong Polytechnic University, Hong Kong.

MoEST (2009). National Indoor Air quality Standards and Implementation Guideline, 2009. Government of Nepal, Ministry of Environment, Science and Technology, Kathmandu, Nepal.

Pradhan, B.B., Dangol, P.M., Maskey, R. \& Pradhan, S. (2012).Rapid urban assessment of air quality for Kathmandu, Nepal. International Centre for Integrated Mountain Development, Kathmandu, Nepal.

Shin, H.H., Burnett, R.T., Stieb, D.M. \& Jessiman, B. (2009). Measuring public health accountability of air quality management. Air Qual Atmos Health, 2, 11-20.

Wang, X.M., Sheng, G.Y., Fu, J.M., Chan, C.Y., Lee, S.C., Chan, L.Y. \& Wang Z.S. (2002). Urban roadside aromatic hydrocarbons in three cities of the Pearl River Delta, People's Republic of China. Atmospheric Environment, 36, 5141-5148.

WHO (2006). Air quality guidelines global update 2005. World Health Organization Regional Office for Europe.

WHO (2010). WHO guidelines for indoor air quality: selected pollutants. World Health Organization Regional Office for Europe.

Wu, S., Deng, F., Niu, J., Huang, Q., Liu, Y. \& Guo, X. (2010). Association of heart rate variability in taxi drivers with marked changes in particulate air pollution in Beijing in 2008. Environmental Health Perspectives, 118, 87-91.

Zhang, K. \& Batterman, S. (2013). Air pollution and health risks due to vehicle traffic. Science of the Total Environment, 450451, 307-316. 